\title{
Replacing Congenitally Missing Central Incisor: A Case Report with a Special Method to Achieve the Optimal Emergence Profile
}

Mark Antal*

Faculty of Dentistry, University of Szeged, Hungary

\begin{abstract}
Aim: In this case report a male patient is presented with a congenitally missing right upper central incisor. Different treatment methods have been combined, including ridge-split technique and flapless surgery.

Methods: The internal tri-lobed impalnt was placed during the bone splitting procedure. Presurgical orthodontic treatment and post-surgical soft-tissue manipulation is described.

Results: The high esthetic outcome, achieved with the screw-retained crown, evaluated with the PES and PI are presented. Results are documented right after final restortion and after one year.

Conclusion: The use of screw-retained temporary composite crowns for soft-tissue contouring is affirmed. One year after rehabilitation the screw-retained press-ceramic crown is still in function without any esthetic compromise. The surgical method described and used in this case report still needs long-term evidence-based evaluation and verification.
\end{abstract}

Keywords: Central incisor; Flapless surgery; Ridge-split; Screwretained crown; Press-ceramic crown; Soft-tissue contouring

\section{Introduction}

Dental patients with congenitally missing front teeth may present with undeveloped alveolar bone, causing challenges in implant reconstruction $[1,2]$. While missing teeth have been successfully replaced by titanium implants in the last decade, dental restoration and surgery still struggles with cases of restoring anterior teeth where the use of implant supported restorations is still a technically sensitive issue [3].

Restoration and management of congenially missing lateral incisors is well documented in literature [4-9]. Maxillary lateral incisor agenesis occurs in 0.8 to $2 \%$ of the population in the permanent dentition phase [10-12]. The agenesis of central incisors is occurring much infrequently, and the presence of congenitally missing central incisor without any combined developmental lesion is real rarity. Therefore it is hard to find any documentation and literature description. Some cases have been described about prosthetic restoration of missing central incisors with implant supported dental bridgework. Abbo and Razoog [13] reported cases of the placement of narrow platform, internal tri-lobed implants, with the restorative solution of 4-unit zirconium fixed partial denture in order to restore the missing mandibular central incisors. Description of the prosthetic replacement of a missing central incisor has also been published, where transformation of the anterior teeth were achieved, with laminate veneers, to simulate a complete dentition. The first premolar was transformed to mimic the esthetics of a canine, the canine to a lateral incisor and the lateral incisor to a central incisor [14].

Implant restoration of a single missing central incisor is rarely documented in the literature, and guidelines, so treatment protocols may vary and depend on the clinicians and the team performing the orthodontic and prosthetic restoration of the patient. In cases of missing central incisors with insufficient space for the tooth, only complicated treatment choices can achieve the planned result.

Moreover, in a growing child or adolescent multi-disciplinary cooperation between the prosthodontist, the oral surgeon and the orthodontist can lead to an optimal outcome [15].

The success of implantation is mainly determined by osseointegration, achieving a stable anchorage between the dental implant and the bone structure [16]. Howeverpositive esthetic outcome is not always in correlation with osseointegration. Patients' rising esthetic demand, together with inadequate pre-surgical anatomy will challenge clinicians [17]. Furthermore, a unique challenge is presented to the dental implant surgeons at sites with atrophic bone [18]. As the current concept of the treatment has moved from "bone driven implantology" to "restoration driven implantology", and the demand for aesthetic restorations and healthy soft tissues around the implant has increased [19], the esthetic success of the implant needs to be planned and evaluated carefully.

For the ideal position of the implant the recipient site often needs modification of, where previously on lay grafts harvested from the hip, maxilla or chin have all been used with success. However, as on lay grafts require secondary surgical site, the harvesting of bone with burs and chisels can cause postoperative morbidity [18]. Among alveolar ridge augmentation techniques, the ridge-split procedure demonstrates many benefits, including no need for a donor surgical site, rare risk of inferior alveolar nerve injury, less pain and swelling, and others [20]. Demetriades et al. [21] have concluded, that "the split crest bone augmentation technique is a valid reconstructive procedure that can be used to augment the buccolingual alveolar defect prior to implant placement providing good bone foundation for placement of implants with desirable width in favorable angulations". Comparing to bone graft techniques, ridge-split bone augmentation will allow placement of implants simultaneously or 3 weeks postoperatively.

To optimize the soft-tissue esthetics, flapless surgical procedures can provide perfect solution, however both flapless and flap implant

*Corresponding author: Mark Antal, Faculty of Dentistry, University of Szeged H-6720 Szeged, Tisza L. Krt. 64, Hungary, Tel: 003630 5255850; E-mail antalmarkdr@gmail.com

Received March 07, 2013; Accepted April 29, 2013; Published May 07, 2013

Citation: Antal M (2013) Replacing Congenitally Missing Central Incisor: A Case Report with a Special Method to Achieve the Optimal Emergence Profile. Surgery S11: 003. doi:10.4172/2161-1076.S11-003

Copyright: (c) 2013 Antal M. This is an open-access article distributed under the terms of the Creative Commons Attribution License, which permits unrestricted use, distribution, and reproduction in any medium, provided the original author and source are credited. 
placement protocols can result in high success rate, but a flapless protocol may provide a better short-term esthetic result [22]. Oliver et al. have concluded, that "flapless procedure for dental implant placement is advantageous for preserving crestal bone and mucosal health, so that this technique increases the success rate of dental implants" [23].

The final outcome of such a case can be described with evaluation of the alterations of soft tissue around the implant with the Pink Esthetic Score (PES) and Papilla Index (PI) at the time of crown placement and 1 year post-loading [24-26].

\section{Diagnosis and Etiology}

A male patient is presented with a congenitally missing right upper central incisor (Figures 1-4). The patient had received a removable denture from his dentist to replace the missing tooth at the age of 16. In order to achieve the optimal esthetic outcome, an orthodontic treatment was performed until the age of 18. The lateral incisors and the left central incisor were moved to the ideal position, and the orthodontic appliance was kept in situ in order to maintain the space until the final prosthetic restoration.

\section{Treatment objectives}

As the available bone was insufficient in the oro-vestibular dimension (Figures 5a and 5b), a bone-condensing technique was used (Meisinger Split Control Bone Expansion Kit, Meisinger USA, LLC, Jacksonville, Fla). The crestal split ridge bone augmentation [22] enabled sufficient bone for the placement of the needed dental implant (Figure 6).

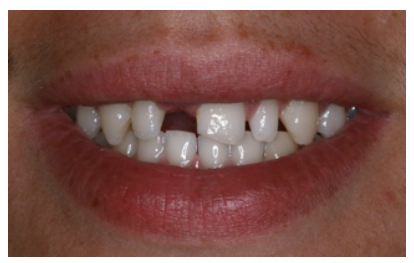

Figure 1: A male patient is presented with a congenitally missing right upper central incisor

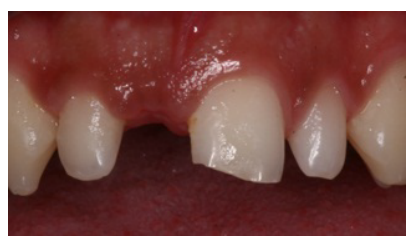

Figure 2: A male patient is presented with a congenitally missing right upper central incisor.

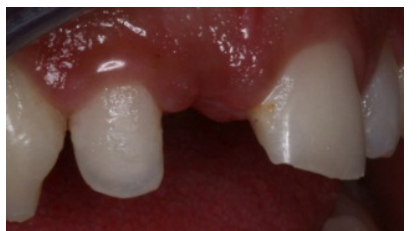

Figure 3: A male patient is presented with a congenitally missing right upper central incisor.

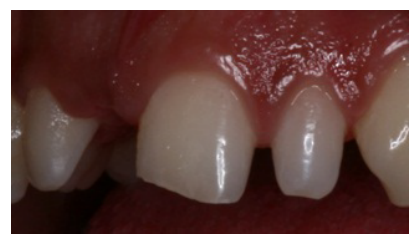

Figure 4: A male patient is presented with a congenitally missing right upper central incisor

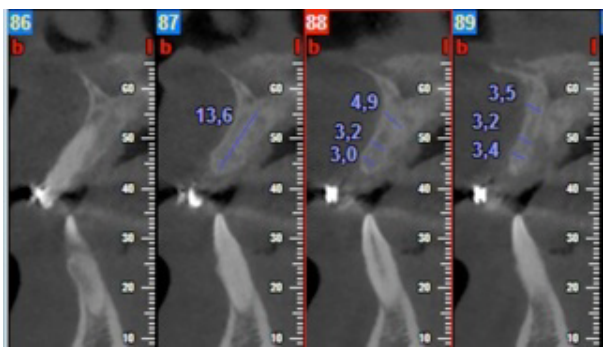

Figure 5a: The oro-vestibular dimension.

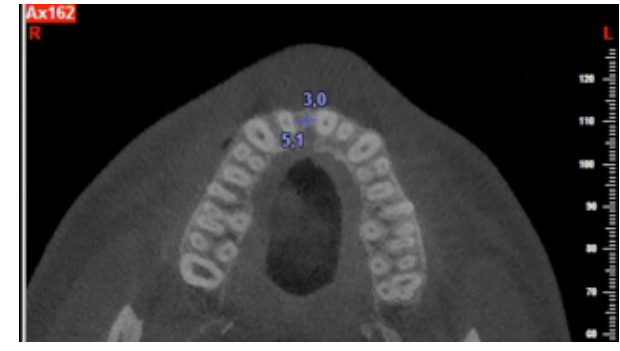

Figure 5b: The oro-vestibular dimension.

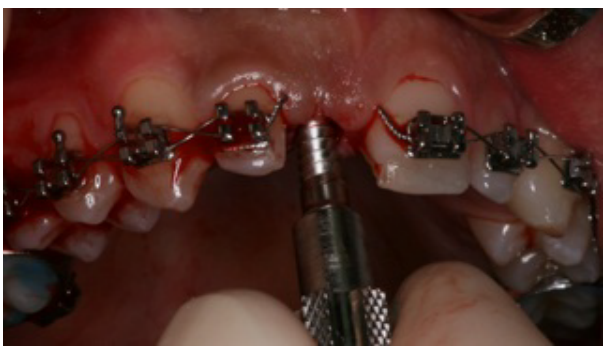

Figure 6: The crestal split ridge bone augmentation

The proper implant selection and themesiodistal, apicocoronal, and orofacialimplant position was determined following the guidelines of Buser et al. [17].

A minimal invasive, transgingival flap design was used, performed with a tissue punch, in order to minimize the surgical trauma to the soft and hard tissues. A precise wound closure was performed with 5.0 nonabsorbable synthetic monofilament sutures repositioning the removed soft tissue, suturing was performed under magnification.

An internal tri-lobed $13 \mathrm{~mm}$ long narrow platform implant was placed (Nobel Replace Tapered Groovy, Nobel Biocare, Göteborg, Sweden) in the site 11 with a cover screw and three months of healing period has followed with monthly control. 
During the healing period a composite crown was attached to the orthodontic wire.

\section{Restoration}

After osseointegration a screw-retained composite crown (Empress Direct, IvoclarVivadent, Schaan, Liechtenstein) was fabricated to form the soft-tissues and achieve esthetic emergence profile (Figure 7). During a three-week period composite was periodically added to the gingival site of the crown, to passively form the attached gingiva (Figure 8). After achieving the optimal gingival contour and the needed form for the planned emergence profile, an impression was taken with two-phase, one time method, using A-silicone impression material (Honigum, DMG Hamburg, Germany).

For final restoration a screw-retained one-piece eMax press-ceramic crown (IvoclarVivadent, Schaan, Liechtenstein) was fabricated.

The final outcome of the treatment was evaluated using the PES and PI (according to Jemt) immediately (Figure 9) and one year after (Figure 10) coronal restoration [26]. Digital photographs were used for the evaluation of the papilla levels.

The photographs were taken perpendicular to the buccal surface at 1:1 magnification, using a Canon EOS 350D digital camera (Canon, Tokyo, Japan) with macro lens and ring flash [27].

\section{Results}

Within the limitations of a case report, the use of screw-retained composite crowns for temporary and screw retained press-ceramic crowns as final restorations can be affirmed. In this current case the combination of split ridge bone augmentation with flapless surgery resulted in a sufficient outcome. The PES was 10 rights after placing the final restoration and 14 at the one year control. PI was at the mesial papilla equally 3 right after restoration and at one year recall, but 2 at the distal papilla at the first measure. This has changed to 3 at the one year follow up also at the distal papilla.

The detailed PES and PI results can be seen in table 1. Pink esthetics and papillae have been successfully formed with this method.

\section{Discussion}

Congenitally missing central incisors can challenge the operator in restoring both function and esthetics. As the restoration has been described and well documented in the literature for lateral incisors and also extracted central incisors, some modifications and combinations of certain treatment options can result in high esthetic outcome with optimal function. The high esthetic demands of the patients and the lack of treatment protocols in such cases can lead the operator to combine different treatment options and solutions.

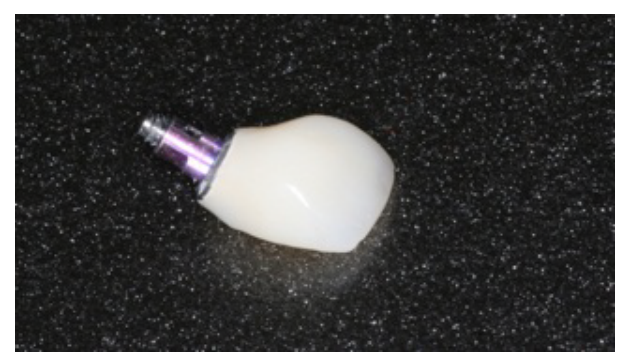

Figure 7: Esthetic emergence profile.

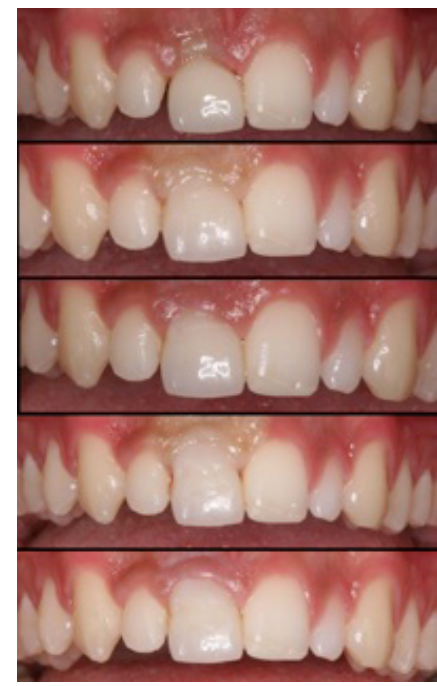

Figure 8: Attached gingival.

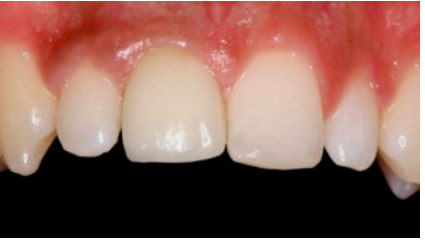

Figure 9: Evaluated using the PES and PI.

\begin{tabular}{|l|c|c|}
\hline & Immediate after restoration & 1 year control \\
\hline PI & & \\
\hline Mesial & 3 & 3 \\
\hline Distal & 2 & 3 \\
\hline PES & 10 & 14 \\
\hline Mesial papilla & 2 & 2 \\
\hline Distal papilla & 1 & 2 \\
\hline Level of soft-tissue margin & 2 & 2 \\
\hline Soft-tissue contour & 1 & 2 \\
\hline Alveolar process & 2 & 2 \\
\hline Soft-tissue color & 2 & 2 \\
\hline Soft-tissue texture & 1 & 2 \\
\hline
\end{tabular}

Table 1: Papilla Index (PI) and Pink Esthetic Score (PES) immediate and one year after final restoration. (Note: the composite filling in tooth 21 has been changed after the final restoration, but before the one year control).

In this case the flapless surgery protocol that has a positive effect on preserving the crestal bone $[23,24]$ has been combined with the well documented ridge-split technique [20]. This method has provided sufficient oro-vestibular bone thickness with leaving both oral and palatal mucosa intact, assuring better wound healing and more predictable esthetic result. Combining these methods might end up in such positive outcome, but the limitations of this technique are not yet defined. Obviously, a minimal overall bone thickness of $2.5-3.0 \mathrm{~mm}$ is needed, and it is essential to have a minimal amount of spongious bone between the oral and buccal cortical, in order to enable splitting. More detailed research might be needed to validate this option and evaluate the limitations.

Successful osseointegration itself, with the correct angulations of the implant might not end up with sufficient esthetics. Prosthetic 
rehabilitation, with detailed soft-tissue contouring has led to the positive outcome of the treatment. As literature describes no significant difference between cemented and screw retained implant crowns in the clinical behaviour of the peri-implant marginal bone or of the periimplant soft tissues [28], but screw retained crowns give the opportunity to be modified several times after placed in situ [29], the usage of screw retained temporary crown was an excellent tool to achieve optimal emergence profile. The same background also explains the final restoration design. Having the opportunity to re-contour or modify the final restoration, together with the option to control oral hygiene and gingival health at the implant-abutment junction, recommends the use of screw-retained restorations even in the esthetic zone. However in some cases, due to the wrong angulations of the dental implant this solution might not be a preferable option.

The use of press-ceramic crowns on dental implants is a well documented solution in the literature [30,31]. Processing ceramic abutments on titanium implants is described in details by the manufacturer.

\section{Conclusions}

Within the limitations of a case report, the use of screw-retained temporary composite crowns for soft-tissue contouring can be affirmed. One year after rehabilitation the screw-retained press-ceramic crown is still in function without any esthetic compromise.

The surgical method described and used in this case report still needs long-term evidence-based evaluation and verification.

\section{Acknowledgement}

The author would like to thank Dr. Gabriella Szalma (orthodontist) Dr. EszterNagy andZsuzsaNógrádi MDT for their excellent work and support.

\section{References}

1. Nissan J, Mardinger O, Strauss M, Peleg M, Sacco R, et al. (2011) Implantsupported restoration of congenitally missing teeth using cancellous bone block-allografts. Oral Surg Oral Med Oral Pathol Oral Radiol Endod 111: 286291.

2. Raghoebar GM, Timmenga NM, Reintsema $H$, Stegenga B, Vissink A (2001) Maxillary bone grafting for insertion of endosseous implants: results after 12 124 months. Clin Oral Implants Res 12: 279-286.

3. Fu PS, Wu YM, Wang JC, Huang TK, Chen WC, et al. (2012) Optimizing anterior esthetics of a single-tooth implant through socket augmentation and immediate provisionalization: a case report with 7 -year follow-up. Kaohsiung J Med Sci 28: 559-563.

4. Rasner SL (2005) Replacing congenitally missing maxillary lateral incisors: assessing treatment options and case report. Dent Today 24: 66, 68, 70 passim.

5. Kokich VO Jr, Kinzer GA (2005) Managing congenitally missing lateral incisors. Part I: Canine substitution. J Esthet Restor Dent 17: 5-10.

6. Vogel RE, Wheeler SL, Casellini RC (1999) Restoration of congenitally missing lateral incisors: a case report. Implant Dent 8: 390-395.

7. Misch CE (2004) Treatment options for a congenitally missing lateral incisor: a case report. Dent Today 23: 90, 92, 94-95.

8. Small BW (1996) Esthetic management of congenitally missing lateral incisors with single-tooth implants: a case report. Quintessence Int 27: 585-590.

9. Garg AK (2002) Treatment of congenitally missing maxillary lateral incisors: orthodontics, bone grafts, and osseointegrated implants. Dent Implantol Update 13: 9-14.
10. Altug-Atac AT, Erdem D (2007) Prevalence and distribution of dental anomalies in orthodontic patients. Am J Orthod Dentofacial Orthop 131: 510-514.

11. Araújo EA, Oliveira DD, Araújo MT (2006) Diagnostic protocol in cases of congenitally missing maxillary lateral incisors. World J Orthod 7: 376-388.

12. Fekonja A (2005) Hypodontia in orthodontically treated children. Eur J Orthod 27: $457-460$.

13. Abbo B, Razzoog ME (2006) Management of a patient with hypodontia, using implants and all-ceramic restorations: a clinical report. J Prosthet Dent 95: 186189.

14. Beznos C (1996) An alternative approach to replacement of a congenitally missing maxillary central incisor: a case report. Quintessence Int 27: 759-762.

15. Tichler HM, Abraham JE (2007) Management of a congenitally missing maxillary central incisor. A case study. N Y State Dent J 73: 20-22.

16. Albrektsson T, Johansson C (2001) Osteoinduction, osteoconduction and osseointegration. Eur Spine J 2: S96-101.

17. Buser D, Martin W, Belser UC (2004) Optimizing esthetics for implant restorations in the anterior maxilla: anatomic and surgical considerations. Int $J$ Oral Maxillofac Implants 19: 43-61.

18. Coatoam GW, Mariotti A (2003) The segmental ridge-split procedure. J Periodontol 74: 757-770.

19. Garber DA, Belser UC (1995) Restoration-driven implant placement with restoration-generated site development. Compend Contin Educ Dent 16: 796 798-802, 804

20. Tolstunov L, Hicke B (2013)Horizontal augmentation through the ridge-split procedure: a predictable surgical modality in implant reconstruction. J Oral Implantol 39: 59-68.

21. Demetriades N, Park JI, Laskarides C (2011) Alternative bone expansion technique for implant placement in atrophic edentulous maxilla and mandible. J Oral Implantol 37: 463-471.

22. Bashutski JD, Wang HL, Rudek I, Moreno I, Koticha T, et al. (2013) The Effect of Flapless Surgery on Single-Tooth Implants in the Esthetic Zone: A Randomized Clinical Trial. J Periodontol.

23. Oliver R (2012) Flapless dental implant surgery may improve hard and soft tissue outcomes. J Evid Based Dent Pract 12: 87-88.

24. Fürhauser R, Florescu D, Benesch T, Haas R, Mailath G, et al. (2005) Evaluation of soft tissue around single-tooth implant crowns: the pink esthetic score. Clin Oral Implants Res 16: 639-644.

25. Lai HC, Zhang ZY, Wang F, Zhuang LF, Liu X, et al. (2008) Evaluation of soft-tissue alteration around implant-supported single-tooth restoration in the anterior maxilla: the pink esthetic score. Clin Oral Implants Res 19: 560-564.

26. Jemt T (1997) Regeneration of gingival papillae after single-implant treatment. Int J Periodontics Restorative Dent 17: 326-333.

27. Si MS, Zhuang LF, Huang X, Gu YX, Chou CH, et al. (2012) Papillae alterations around single-implant restorations in the anterior maxillae: thick versus thin mucosa. Int J Oral Sci 4: 94-100.

28. Vigolo P, Mutinelli S, Givani A, Stellini E (2012) Cemented versus screwretained implant-supported single-tooth crowns: a 10-year randomised controlled trial. Eur J Oral Implantol 5: 355-364.

29. Sailer I, Mühlemann S, Zwahlen M, Hämmerle CH, Schneider D (2012) Cemented and screw-retained implant reconstructions: a systematic review of the survival and complication rates. Clin Oral Implants Res 23: 163-201.

30. Mitsias M, Koutayas SO, Wolfart S, Kern M. Influence of zirconia abutment preparation on the fracture strength of single implant lithium disilicate crowns after chewing simulation. Clin Oral Implants Res. 2012 Oct 29.

31. Reich S, Schley J, Kern T, Fiedler K, Wolfart S (2012) Examples of model-free implant restorations using Cerec inLab 4.0 software. Int J Comput Dent 15 207-225. 